\title{
A Survey on Essential Strategies for Avoiding Cloud Data Leaks
}

\author{
Ch. Sudhakar ${ }^{1}$ and S. NagaMallik Raj ${ }^{2}$ \\ Asst. Prof, Department of Computer Science and Engineering, Vignan's Institute of \\ Information Technology, Visakhapatnam, AP, India \\ ${ }^{1}$ sudhakarcheetirala@gmail.com, ${ }^{2}$ mallikblue@gmail.com
}

\begin{abstract}
As of late, there has been a tremendous development from putting away information the customary route, as the cloud has developed and turned into the better answer and alternative for organizations and associations alike. Notwithstanding, this has additionally prompted a development in digital culprits and information breaks now that somebody can get to touchy archives from their lounge room love seat. In that capacity, cloud information spills have turned into a very regular issue for organizations. More news has examined approaches to counteract breaks, and you can discover a plenty of articles that discuss about huge and little organizations alike being assaulted. Therefore, knowing how to keep a cloud information spill is the initial phase in protecting your business and data. In this paper there are a couple of the best and most straightforward methodologies to maintain a strategic distance from cloud information spills.
\end{abstract}

Keywords: Cloud computing, Encryption, Security, Password, Backup

\section{Introduction}

On the off chance that we store business information which is exceptionally touchy in a private cloud occurrence, on the off chance that it is coincidentally presented to the web, at that point it is called as a cloud spill.

Endeavor informational indexes, regularly taken care of by outsider data examination organizations, are frequently put away decoded in the cloud, with the desire that their information lives inside one of these private pockets.

Yet, distributed storage alternatives like Amazon's S3 enable clients to open their capacity to the web on the loose. It ought to be worried here that $\mathrm{S} 3$ basins are private of course. This implies each cloud break including an Amazon S3 stockpiling occurrence has had its consents changed sooner or later by an administrator taking care of the information. At the point when these unknown open authorizations are permitted, the limit between "the cloud" and the web breaks down. This information at that point ends up open to anybody, equivalent to your preferred site.

Passed on collecting affiliations may be gotten to through a help set up cloud PC advantage, a web advantage application programming interface (API) or by applications that utilization the API, for instance, cloud work area storing up, an appropriated amassing section or Webbased substance association structures [1].

Article history:

Received (July 18, 2019), Review Result (August 26, 2019), Accepted (October 4, 2019) 


\section{What is cloud computing?}

Distributed computing can make life simpler and associations increasingly coordinated. Be that as it may, they can likewise represent a noteworthy issue with regards to your information security. So as to more readily comprehend your information, you have to see how your information can spill in any case.

The danger of information spillage increments as more representatives utilize their own gadgets for work without a severe and vigorous security strategy set up. At the point when representatives utilize these gadgets to get to capacity administrations (like Dropbox or OneDrive) to telecommute or on the train, there is an expanded hazard for a security rupture, particularly when more established forms of working frameworks are utilized. This potential hazard isn't totally moderated by organization provided IT gadgets either, as associations with unbound systems can without much of a stretch lead to an information hack [2][9].

Another manner by which delicate information can be spilled is because of an unintentional human mistake. Putting away passwords and delicate individual information in a plain content document or on memory sticks can mean it's defenseless if an inappropriate individual gets their hands on it.

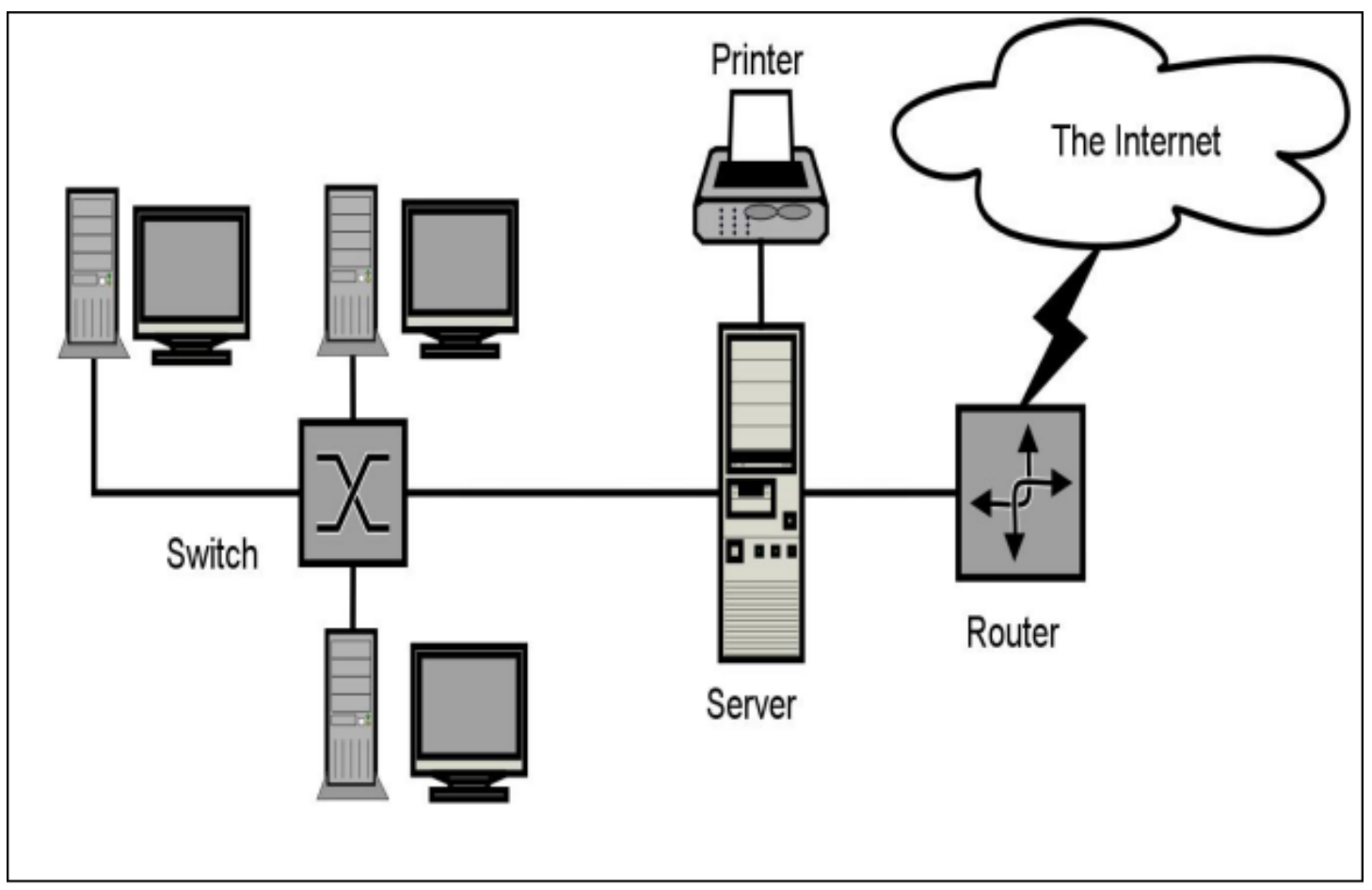

Figure 1. Cloud computing [2]

For it to be considered "cloud computing," you have to get to your information or your projects over the Internet, or in any event, have that information matched up with other data over the Web. In a major business, you may know everything to think about what's on the opposite side of the association; as an individual client, you may never have any thought what sort of huge information handling is going on the opposite end. The final product is the same: with an online association, distributed computing should be possible anyplace, whenever. 


\section{Pros and cons of cloud data}

\subsection{Pros}

Lower straightforward costs and decreased system costs.

Simple to build up your applications.

Scale up or down at short notice.

Pay for what you use.

General ecological advantage (bring down carbon emanations) of numerous clients proficiently sharing expansive frameworks. (Be that as it may, see the container beneath.)

\subsection{Cons}

Higher progressing working expenses. Could cloud frameworks work out more costly?

More noteworthy reliance on specialist co-ops. Would you be able to get issues settled immediately, even with SLAs?

Danger of being bolted into restrictive or seller suggested frameworks? How effortlessly would you be able to relocate to another framework or specialist organization on the off chance that you have to?

What happens if your provider all of a sudden chooses to quit supporting an item or framework?

protection and security dangers of putting significant information on another per son's framework in an obscure area? Reliance on a dependable Internet association[3][4].

\section{Strategies for avoiding cloud data leaks}

\subsection{Map your security needs for your cloud deployment}

You ought to recognize the information you require scrambled, and delineate an arrangement with your cloud specialist organization to organize delicate information. On the off chance that your business group is utilizing the cloud for video introductions and designs available for open utilize, just the record data ought to be encoded [6][7].

\subsection{Before working with a CSP understand the details of service}

The client assertion generally traces the points of interest of your arrangement. Get some information about any subtle elements let alone for the client consent to elucidate how, when and where your information is put away, particularly if utilizing an open cloud. Make a point to look for anything that could disregard your organization's protection arrangement.

\subsection{By maintaining organization-wide awareness around data security}

In a few circumstances, information security relies upon your online activities. In the event that you get to cloud information on an open PC or over an unreliable association, your information might be defenseless. Try not to enable any PC to reserve passwords and logins. Make a point to log out from each site or record once you're finished getting to information. Maintain a strategic distance from unsecured Wi-Fi hotspots at whatever point conceivable. These associations leave your data powerless against programmers.

\subsection{Encrypt data}


This ought to be an easy decision. The advantage of scrambling information can be ten times as programmers require a particular encryption key to really read the information put away in your cloud. Regardless of whether your information is very still or in movement, it ought to be scrambled throughout the day, consistently.

Despite the fact that we began with this one, encryption is all the more frequently the last resistance you have against digital lawbreakers. Toward the day's end, on the off chance that they can in any case get to your cloud information, with encryption its absolutely impossible they can really utilize it.

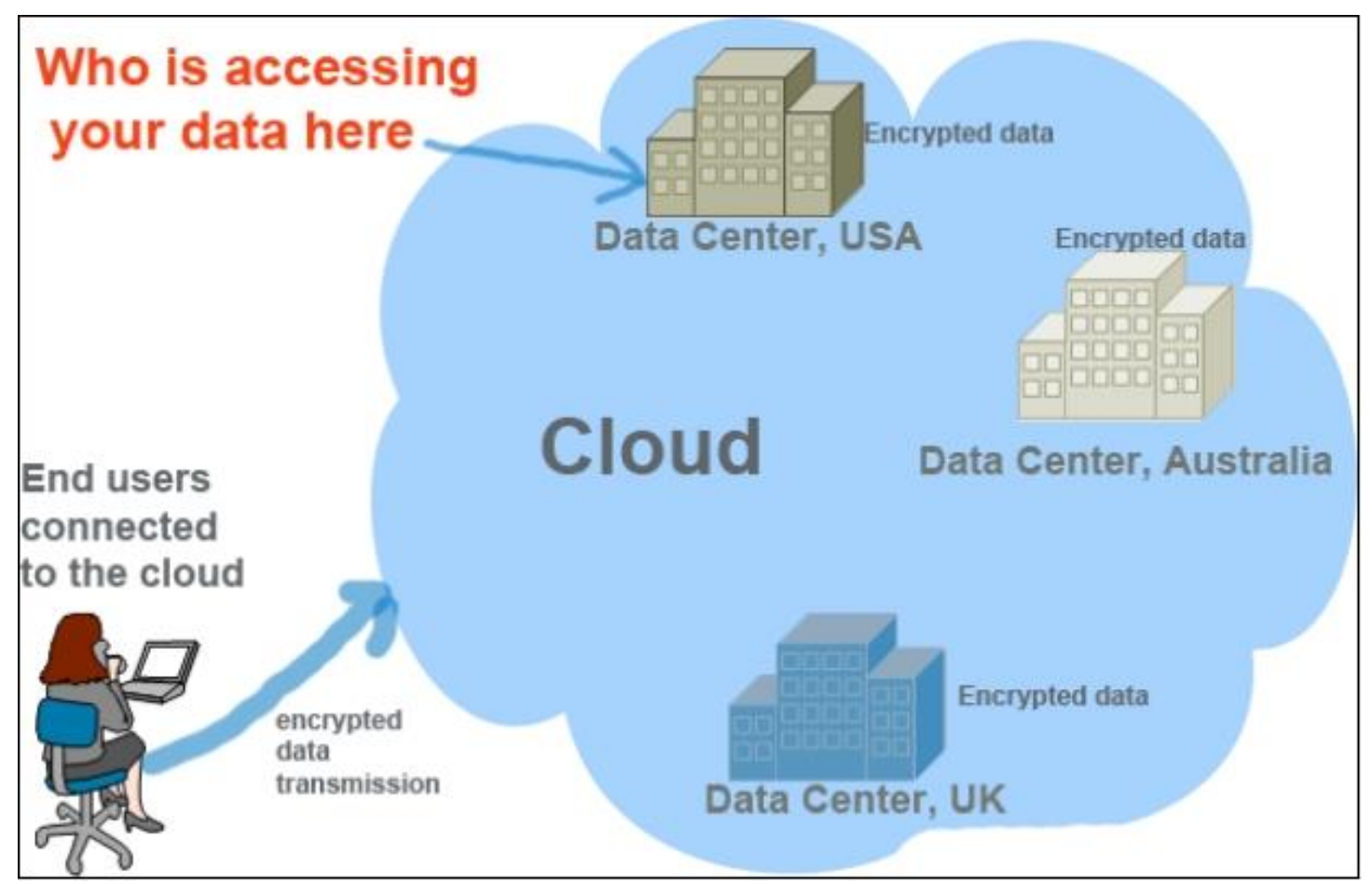

Figure 2. Encryption of cloud data [5]

\subsection{Cloud cryptography for secure access}

Azure use cryptography to offer a layer of data security at a structure level and empowers secure access to whoever needs shared cloud associations. Clients get an open and private key merge with a particular ID. Cryptographic passed on enlisting can also confine arrange blockage.

\subsection{Protect data at rest and in transit with a cloud access security broker}

Cloud Access Security Broker (CASB) is another way you can scramble information and control your own particular keys. A CASB offers a solitary purpose of perceivability and access control into any cloud application in an expansive endeavor. The control comes through relevant access control, encryption for information very still and spillage insurance of information. A CASB intercedes the associations between cloud applications and the overall population through a few API connectors and intermediaries.

\subsection{Change passwords}


You've heard it once; you'll hear it once more: be more intelligent about your passwords. Late examinations have demonstrated that it's not simply an issue of making a Jackson Pollock of letters and numbers. Truth be told, the hardest passwords to break are phrases. Try not to chance your customer's agreements or Mastercard numbers, your Social Security Number, or your email since you jump at the chance to utilize your wedding commemoration as each secret word.

Shoot for a more extended expression, something senseless to enable you to recall. Additionally, investigate putting resources into a watchword program like LastPass that stores every one of your passwords in a sheltered place, so you just need to recollect one secret word. LastPass and other secret key administration devices like Dashlane or LogMeOnce can likewise enable you to produce hard-to-break passwords [8].

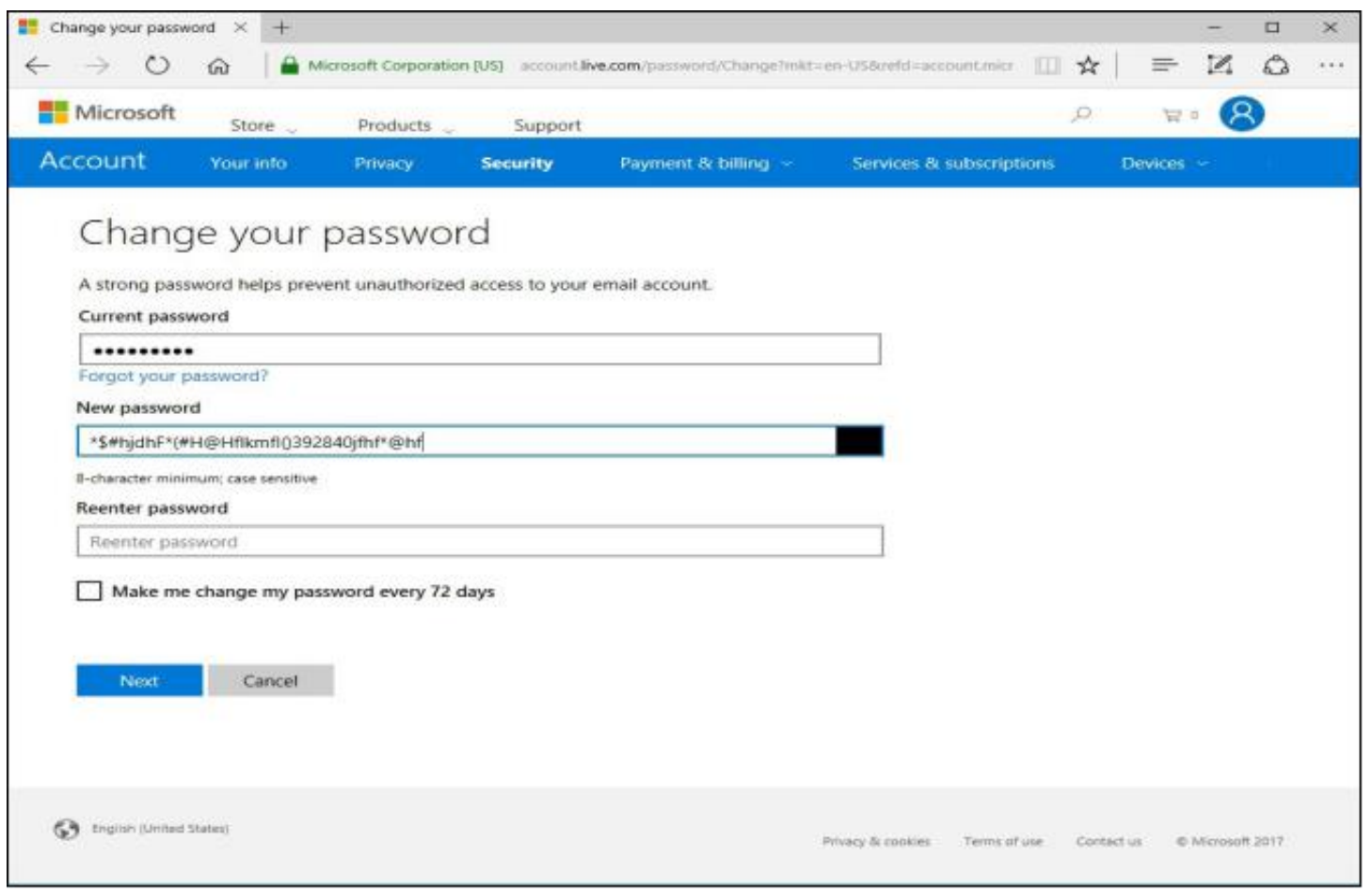

Figure 3. Change the password regularly [6]

\subsection{Train}

Regardless of whether you have a little association or a vast organization, preparing your workers and temporary workers to be keen about their information utilize and get to is foremost to maintain a strategic distance from cloud information spills. With such huge numbers of gadgets hopping onto Wi-Fi and systems, it's simple for programmers to sneak onto less secure gadgets and rapidly access your system, servers and cloud.

Set aside the opportunity to instruct your workers on what a phishing email resembles, demonstrate to them industry standards to better produce passwords, and show them to dump spreadsheets to store that watchword information. Try not to expect that best level executives are settling on the best choices around touchy information either, and don't accept that everybody in your association knows how to impeccably counteract information spills. 
By setting aside the opportunity to instruct workers now, you can spare yourself a gigantic cerebral pain not far off (and a considerable amount of cash, as well).

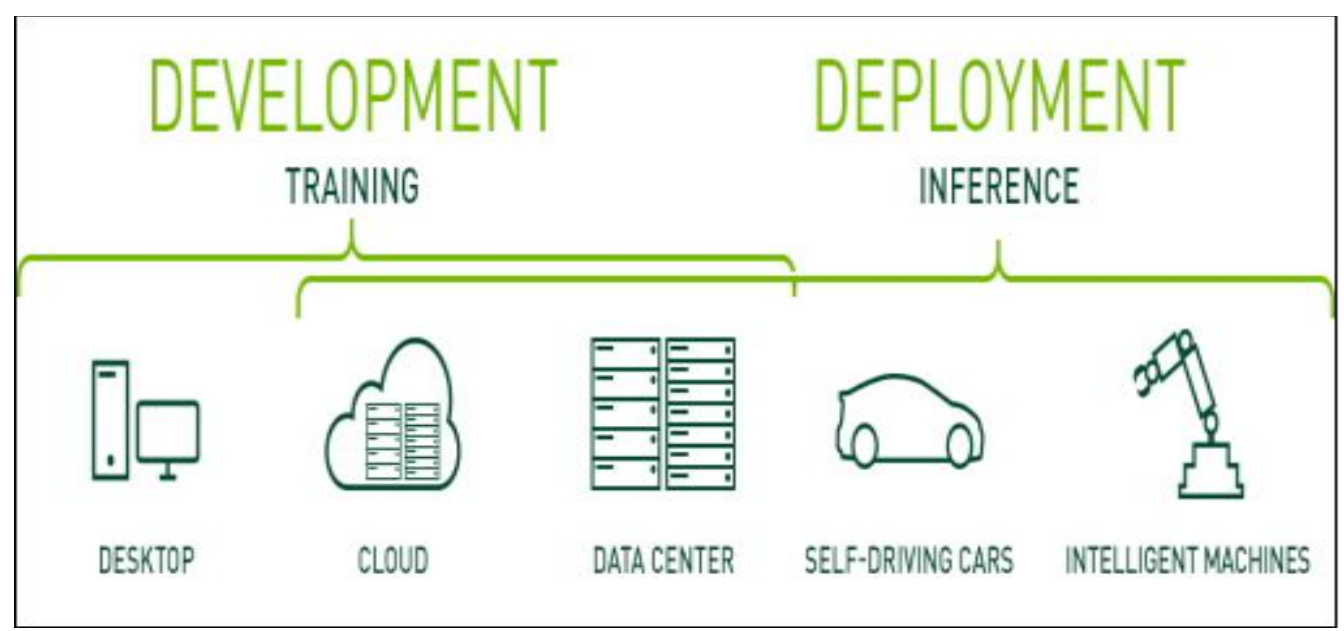

Figure 4. Training the employees to be smart about their data use [8]

\subsection{Backup your data}

Information reinforcement may feel like a "relic of past times" since hi, we have the cloud now, so some may figure we don't have to reinforce our information any longer. Be that as it may, that is not valid. A ton of information misfortunes and ruptures have been caused by physical reinforcement drives being stolen, yet that was likewise a "relic of days gone by".

Today, organizations can utilize associations that utilization the web to reinforce, disposing of the danger of drives or tapes being stolen or lost. Obviously, there is the dread that if your cloud information can be hacked, so can these web reinforcements, however the greater part of these organizations has put resources into first class security conventions. You're unquestionably getting what you pay for with them. Look at organizations like IDrive, SOS Online reinforcement, or Carbonite among others. Shockingly better, put resources into both physical and online reinforcement choices so you'll be secured regardless of whether one of your reinforcements falls flat.

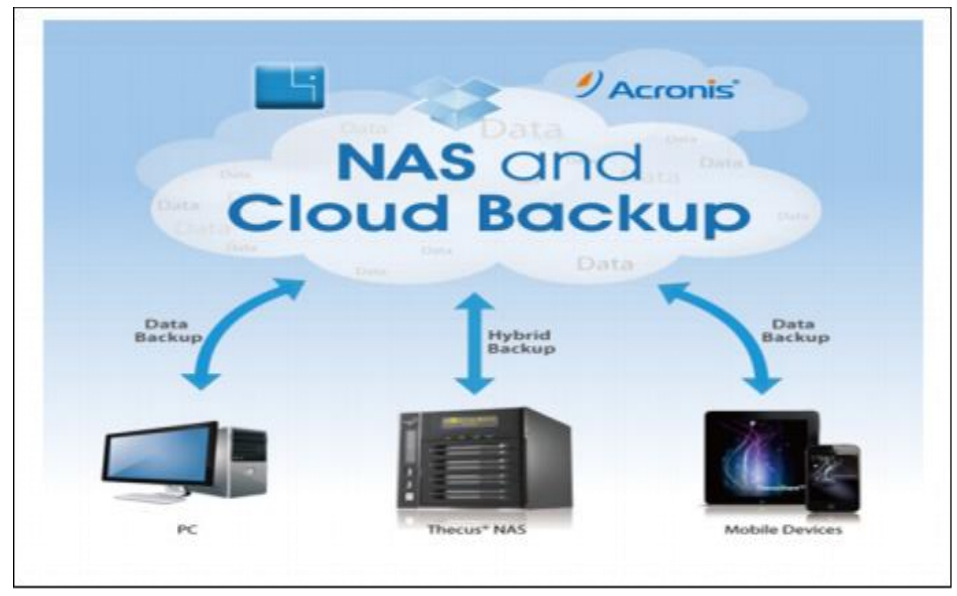

Figure 5. Backup the cloud data [5] 


\subsection{Set permissions}

A colossal piece of why information spills happen is on account of fired workers still approach or section level representatives can get to executive level information. Furthermore, more often than not we don't understand it. Remain over the consent inside your systems and servers to ensure just the ideal individuals can get to the correct information.

Client consents are in reality simple to set up through your IT office and can be effortlessly followed and kept up as long as you make it a point to remain over work force changes. Doing as such can bring down the danger of somebody reordering touchy information and having that get coincidentally sent in an email to the wrong individual who may not be a protected system.

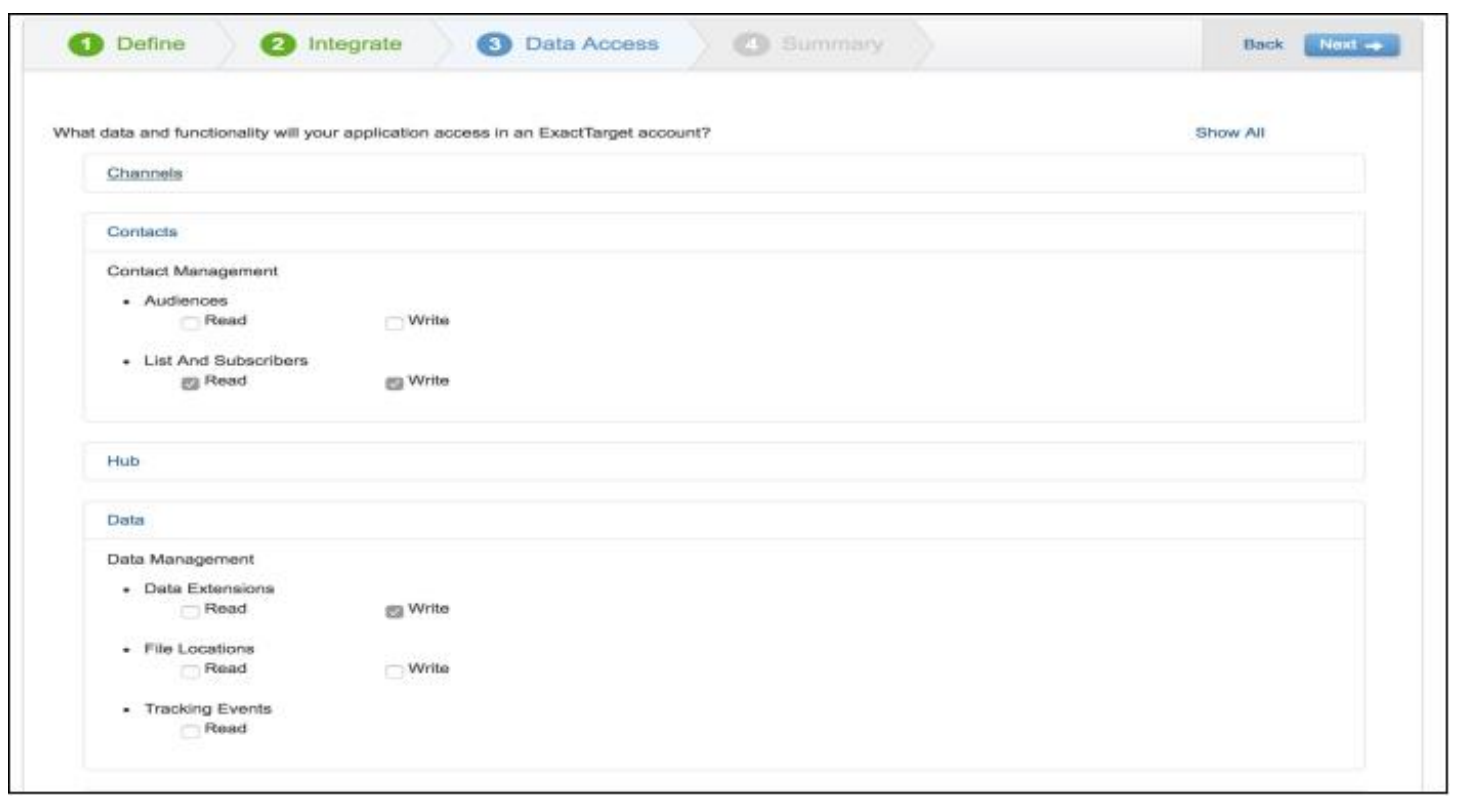

Figure 6. Setting the permissions for cloud data [4]

\section{Conclusion}

This Literature audit depicts three key reasons for capability between cloud-based associations and applications and relative ones got to over the web. One is the likelihood of adaptability (which is an equivalent game plan to flexibility): a cloud association or application isn't constrained to what a specific server can conform to; it can typically widen or get its ability as required.

Another is the dynamic idea of cloud associations: they're not given from a particular, static server. A third, related thought is that cloud associations are reliable - paying little mind to whether you're an architect or an end customer, everything seems, by all accounts, to be indistinguishable, regardless, wherever, and with whatever contraption you use it [9].

\section{References}

[1] P. Mell and T. Grance, "The NIST definition of cloud computing," NIST special publication, (2011)

[2] Q. Zhang, L. Cheng, and R. Boutaba, "Cloud computing: state-of-the-art and research challenges," Journal of Internet Services and Applications, vol. 1, no. 1, pp. 7-18, Apr, (2010) DOI: 10.1007/s13174-010-0007-6

[3] W. a Jansen, "Cloud hooks: Security and privacy issues in cloud computing," in 2011 44th Hawaii International Conference on System Sciences, pp.1-10 (2011) DOI: 10.1109/HICSS.2011.103 
[4] S. Berman and L. Kesterson-Townes, "The power of cloud. driving business model innovation," IBM Institute for Business, (2012)

[5] Vijaya Lakshmi Paruchuri., "Cloud computing for smart grids," International Journal of Cloud-Computing and Super-Computing, vol. 3, no.2, pp.19-26, (2016) DOI:10.21742/IJCS.2016.3.2.03

[6] Kondapalli Kanaka Rao, "Cloud computing to develop applications," International Journal of CloudComputing and Super-Computing, vol. 4, no. 1, pp:9-14, (2017) DOI:10.21742/IJCS.2017.4.1.02

[7] N. Vaishnava Dhaatri, "Cloud storage systems in service diversity," International Journal of Cloud-Computing and Super-Computing, vol. 4, no. 1, pp:15-20, Jun, 2017, (2017) DOI:10.21742/IJCS.2017.4.1.03

[8] Durga Bhavani Dasari, "Cloud-based venue recommendation framework," International Journal of CloudComputing and Super-Computing, vol. 4, no. 1, pp:21-26, (2017) DOI:10.21742/IJCS.2017.4.1.04

[9] Anand Mishra, "The review of trends in smart grid and its applications," International Journal of CloudComputing and Super-Computing, vol. 4, no. 1, pp:27-34, (2017) DOI:10.21742/IJCS.2017.4.1.05 